\title{
Metabolic Syndrome in HIVIAIDS Patients at the Tiko Central Clinic and Cottage Hospital in Cameroon: Influence on Cardiovascular Risk and Predictors
}

\author{
Njeodo Njongang Vigny ${ }^{1,3,}$, , Jules Clement Nguedia Assob ${ }^{1,2}$, Achidi Eric Akum ${ }^{4}$ \\ ${ }^{1}$ Department of Medical Laboratory Sciences, University of Buea, Buea, Cameroon \\ ${ }^{2}$ Department of Biomedical Sciences, University of Buea, Buea, Cameroon \\ ${ }^{3}$ Department of Medical Laboratory Sciences, Maflekumen Higher Institute of Health Sciences Tiko, Tiko, Cameroon \\ ${ }^{4}$ Department of Biochemistry and Molecular Biology, University of Buea, Buea, Cameroon
}

\author{
Email address: \\ N.Vigny64@gmail.com (N. N. Vigny) \\ ${ }^{*}$ Corresponding author
}

\section{To cite this article:}

Njeodo Njongang Vigny, Jules Clement Nguedia Assob, Achidi Eric Akum. Metabolic Syndrome in HIV/AIDS Patients at the Tiko Central Clinic and Cottage Hospital in Cameroon: Influence on Cardiovascular Risk and Predictors. Cardiology and Cardiovascular Research. Vol. 4, No. 3, 2020, pp. 104-110. doi: 10.11648/j.ccr.20200403.15

Received: June 27, 2020; Accepted: July 7, 2020; Published: July 17, 2020

\begin{abstract}
Highly active anti-retroviral therapy (HAART) use by HIV patients since the mid-1990's has led to a significant drop in HIV mortality. However, HAART and HIV related metabolic syndrome (hypertriglyceridaemia, reduced HDL-c, abdominal obesity, hypertension, and insulin resistance) is associated with increased cardiovascular risk in aging HIV sero-positive patients. This study was aimed at investigating the predictors of metabolic syndrome and influence of metabolic syndrome on cardiovascular (CV) risk amongst persons living with HIV on HAART. This is a hospital-based case-control study. The cases were HIV sero-positive individuals on HAART for at least 6 months and controls were HIV sero-negative individuals. Out of 135 participants, $74(54.8 \%)$ were females amongst which 53/75 (70.7\%) were in the cases group and 21/60 (35\%) were in the control group. The mean age of the participants was $42.04( \pm 9.61)$ years. HIV-infected participants at moderate CV risk based on the DAD risk calculator were more frequently diagnosed with metabolic syndrome based on the International Diabetes Federation (IDF) criteria with high statistical significance than those at low CV risk $(5 / 19-26.3 \%$ vs. $12 / 55-21.8 \%, \mathrm{P}=<0.001)$. Bivariate analysis of metabolic syndrome predictors in the study population revealed that gender is associated with increased odds of metabolic syndrome (OR: 5.376, 95\% CI: $1.907-15.153$; $\mathrm{P}=0.001)$. Gender was the only predictor associated with metabolic syndrome (OR: 6.958, CI: 2.317-20.896; $\mathrm{P}=0.001$ ) following multivariate analysis of gender, vegetables or fruits intake, vigorous physical activity and family history of CVD and females were 7 times more likely to develop metabolic syndrome than males. More HAART-treated HIV patients at moderate CVD risk develop metabolic syndrome than those at low CVD risk. Female HIV patients on HAART have higher chances of developing metabolic syndrome compared to their male counterparts. HIV patients particularly females should be screened early for metabolic syndrome following HAART initiation.
\end{abstract}

Keywords: Metabolic Syndrome, HIV, HAART, Cardiovascular Risk, Predictors

\section{Introduction}

Highly active anti-retroviral therapy (HAART) use by HIV (human immunodeficiency virus) patients since the mid1990's has led to a significant drop in HIV related mortality [1]. Nevertheless, metabolic disorders (hypertriglyceridaemia, reduced HDL-c, abdominal obesity, hypertension, and insulin resistance) jointly termed metabolic syndrome is linked to HIV and HAART and associated with elevated cardiovascular disease risk in these patients as they age [2].

A recent study demonstrated that an association exists between HAART and metabolic syndrome and, between metabolic syndrome and increased cardiovascular risk in HAART experienced HIV individuals [3]. Studies conducted in Mexico and Australia reported that more HIV patients on HAART at high 
CV (cardiovascular) risk are diagnosed with metabolic syndrome and incident metabolic syndrome is significantly associated with increased CVD risk respectively [4, 5]. Magdalena et al in 2008 revealed that HIV infection is independently associated with metabolic syndrome in adult female subjects [6]. Predictors of metabolic syndrome among HIV-infected individuals under ART from current reports include age, low physical activity, smoking, and gender amongst others [7, 8].

The prevalence of metabolic syndrome is significantly much higher in HIV sero-positive patients on HAART compared to HAART naïve patients and nearly similar (and insignificant) between HIV-infected and HIV-uninfected individuals [9, 10]. In Cameroon, HAART coverage has drastically risen from $26 \%$ in 2013 to $55 \%$ in 2018 [11, 12]. However, little is known about the predictors of metabolic syndrome and its influence on cardiovascular risk in HIV patients on HAART. In this light, therapeutic and lifestyle interventions geared towards metabolic syndrome and its predictors with a view of preventing cardiovascular events have been limited. This study was therefore aimed at investigating the predictors of metabolic syndrome and influence of metabolic syndrome on cardiovascular risk in HIV sero-positive subjects on HAART attending the Tiko Central Clinic and Cottage hospital in Cameroon.

\section{Materials and Methods}

\subsection{Study Duration, Setting, and Sampling Technique}

This study was conducted over a four-month period, from March to June 2016, at the treatment center of people living with HIV/AIDS, at the Tiko Central Clinic and Cottage hospital. Over 1500 patients receive their treatment at this center. The patients attend the clinic once a month for clinical evaluation and refill of anti-retroviral therapy (ART). A consecutive sampling technique was employed to recruit eligible participants.

\subsection{Ethical Considerations}

The goals of the study, research procedure, risks and benefits of this research were explained to the study participants and only consenting individuals were included in the study. Ethical approval was obtained from the Faculty of Health Sciences Institutional Review Board (FHSIRB) of the University of Buea, Cameroon (reference number: 2014-020514). Administrative authorizations were obtained from the following authorities: regional delegate of public health in Buea, district medical officer in Tiko, director of human resource in Limbe, and from the chief medical officer in Tiko.

\subsection{Inclusion and Exclusion Criteria}

The study population included all adult HIV sero-positive and HIV sero-negative persons attending the Tiko Central Clinic and Cottage hospital for routine health assessment. We included all people living with HIV/AIDS (PLWHA) aged at least 25 years (because QRISK 2-2016 calculator estimates the risk of individuals developing a cardiovascular disease in the age range, 25-84 years) and excluded patients on highly active anti-retroviral therapy (HAART) for less than 6 months including defaulters of treatment regimen, pregnant and lactating women, those with documented hypertension, diabetes and dyslipidemia before commencing HAART and those with any acute illness that required medical/surgical treatment or admission. HAART was defined as the use of $\geq 2$ nucleoside reverse transcriptase inhibitors (NRTIs) and at least one non-nucleoside reverse transcriptase inhibitor (NNRTI); or $\geq 2$ NRTIs and at least one protease inhibitor (PI).

\subsection{Administration of Questionnaires}

A structured questionnaire was used to collect sociodemographic data from the participants while their medical records were accessed to obtain clinical information such as their recent CD4+ $\mathrm{T}$ cell count, HIV status, and type and duration of HAART regimen. Following a 10 minute resting period, while a participant was seated, 2 blood pressure measurements (systolic and diastolic) were taken in the left arm with an interval of 3 minutes using a wrist digital blood pressure monitor. The average blood pressure reading was calculated and used as the participants' actual blood pressure. Waist circumference (WC) was measured to the nearest $0.1 \mathrm{~cm}$ with patients wearing light clothing at the midpoint between the lowest rib and the iliac crest using an inelastic tape in light contact with but not compressing the skin. The weight of each participant was measured using a Kinlee calibrated weighing scale in light clothing, with shoes off. Height was measured using a stadiometer to the nearest $0.1 \mathrm{~cm}$.

\subsection{Blood Collection and Analysis}

Following this, $3 \mathrm{ml}$ of venous blood was obtained, under strict aseptic conditions, after an overnight fast (8-12 hours). Fasting blood glucose was measured using the Accu Chek ${ }^{\circledR}$ Compact Plus glucometer at the spot. Serum was then collected and stored in eppendorf tubes until analysis. Lipid profiles of the participants' sera were later measured in batches using a MINDARY spectrophotometer (BA-88A semi-auto chemistry analyser with touch-screen and pop-up keypad) according to the manufacturer's instruction. Triglycerides level was measured based on a Glycerol phosphate oxidase method. HDL-c level was measured based on the Chemical precipitation technique in the presence of phosphotungstic acid and $\mathrm{Mg}^{2+}$ ions.

\subsection{Definition of Operational Terms}

Metabolic syndrome was defined based on the International Diabetes Federation (IDF) criteria. According to IDF criteria, metabolic syndrome was defined as having abdominal obesity (waist circumference of $80 \mathrm{~cm}$ in women and $94 \mathrm{~cm}$ in men or $\mathrm{BMI} \geq 30 \mathrm{~kg} / \mathrm{m}^{2}$ ) and at least two of the following components: I) Elevated fasting glucose: $\geq 100 \mathrm{mg} / \mathrm{dl}$ or diabetes mellitus; II) Elevated triglycerides: $\geq 150 \mathrm{mg} / \mathrm{dl}$ or treatment; III) Reduced HDL-c: $<40 \mathrm{mg} / \mathrm{dl}$ in men and $<50 \mathrm{mg} / \mathrm{dl}$ in women or treatment; IV) Elevated blood pressure (Hypertension): SBP $\geq 130 \mathrm{mmHg}$ or DBP $\geq 85 \mathrm{mmHg}$ or treatment [13]. 
The following parameters were defined as follows: Physical inactivity (failure to engage in physical activities, recreation or work that lasted $<30$ mins per day for $<3$ times in a week) and insufficient fruit or vegetable consumption (failure to consume fruit or vegetable daily).

\subsection{Data Analysis}

Data analysis was performed on SPSS version 22.0 using Chi-square $\left(\chi^{2}\right)$ test, bivariate and multivariate logistic regression. QRISK®2-2016 risk calculator was used to determine the 10- year risk of developing a coronary heart disease [14]. The 10-year CVD risk was calculated using QRISK2-2016 risk equation for each participant by entering the following variables: age, gender, ethnicity, smoking status, diabetes status, Agina or heart attack in a first degree relative $<60$ years, chronic kidney disease (stage 4 or 5), atrial fibrillation, rheumatoid arthritis, SBP, cholesterol/HDL ratio, weight, height and current treatment for high blood pressure. Participants were regarded as low risk, moderate risk, or high risk when the risk score for developing CVD in 10 years was $<10 \%, 10-20 \%$ or $>20 \%$ respectively.

D. A. D (Data collection on Adverse events of anti-HIV Drugs) risk calculator was used to determine the 5-year risk of myocardial infarction, coronary heart disease and CVDs [15]. Variables included in the 5-year DAD risk estimation tool were: age, sex, height, weight, SBP, TC, HDL-C, diabetes mellitus, smoking status, family history of CVD, current use of abacavir, indinavir, or lopinavir and duration on indinavir and lopinavir. The risk of developing coronary heart disease in the next 5 -years was regarded as low $(<1 \%)$, moderate $(1-5 \%)$, high $(5-10 \%)$, or very high $(>10 \%)$.

QRISK2-2016 risk calculator was developed from a prospective cohort study conducted within a large UK primary care population in which the probability of an individual developing a cardiovascular disease in 10 years was calculated [29]. In contrast, DAD risk equation was developed from the DAD cohort study in which HIV patients on HAART were followed for 4.8 years and their risk of developing a coronary heart disease in 5 years (follow-up time) was calculated [31].

\section{Results}

A total of 135 participants were recruited, 75 (55.6\%) were HIV sero-positive amongst which $53(70.7 \%)$ were females and $60(44.4 \%)$ were HIV sero-negative amongst which 39 $(65 \%)$ were males. The mean age was $42.04( \pm 9.61)$ years in the HIV sero-positive group and $39.00( \pm 11.3)$ years in the control group. The median duration on HAART was 42.0 (18 -82) months (Table 1).

Table 1. Demographic Characteristics of Study Population.

\begin{tabular}{|c|c|c|c|c|}
\hline Parameter & & HIV seropositive group $(n=75)$ & HIV seronegative group $(n=60)$ & Total $(n=135)$ \\
\hline \multirow{2}{*}{ Gender } & Male & $22(29.3)$ & $39(65.0)$ & $61(45.2)$ \\
\hline & Female & $53(70.7)$ & $21(35.0)$ & $74(54.8)$ \\
\hline Age (years) & $<40$ years & $34(45.3)$ & $39(65.0)$ & $73(54.1)$ \\
\hline \multirow{3}{*}{ Occupation } & Salary employed & $43(57.3)$ & $45(75.0)$ & $88(65.2)$ \\
\hline & Self employed & $22(29.3)$ & $12(20.0)$ & $34(25.2)$ \\
\hline & Unemployed & $8(10.7)$ & $2(3.3)$ & $10(7.4)$ \\
\hline \multirow{3}{*}{ Marital status } & Married/Cohabitation & $38(50.7)$ & $33(55.0)$ & $71(52.6)$ \\
\hline & Single & $32(42.7)$ & $23(38.3)$ & $55(40.7)$ \\
\hline & Divorced & $5(6.7)$ & $4(6.7)$ & $9(6.7)$ \\
\hline \multirow{4}{*}{ Level of education } & No formal education & $4(5.3)$ & $5(8.3)$ & $9(6.7)$ \\
\hline & Primary & $39(52.0)$ & $28(46.7)$ & $67(49.6)$ \\
\hline & Secondary & $28(37.4)$ & $18(30.0)$ & $46(34.1)$ \\
\hline & Tertiary & $4(5.3)$ & $9(15.0)$ & $13(9.6)$ \\
\hline \multirow{2}{*}{ CD4+ T cell count* (cells $/ \mu \mathrm{L})$} & $<250$ & $17(23.6)$ & - & - \\
\hline & $>500$ & $28(38.9)$ & - & - \\
\hline Duration of HIV infection (months) & Median (IQR) & $63(28-67)$ & - & - \\
\hline Duration of HAART (months) & Median (IQR) & $42(18-82)$ & - & - \\
\hline \multirow{5}{*}{ Type of HAART regimen } & $\mathrm{TDF}+3 \mathrm{TC}+\mathrm{EFV}$ & $47(62.7)$ & - & - \\
\hline & $\mathrm{AZT}+3 \mathrm{TC}+\mathrm{NVP}$ & $23(30.6)$ & - & - \\
\hline & $\mathrm{AZT}+3 \mathrm{TC}+\mathrm{EFV}$ & $2(2.7)$ & - & - \\
\hline & $\mathrm{TDF}+3 \mathrm{TC}+\mathrm{LPV}+\mathrm{RTV}$ & $2(2.7)$ & - & - \\
\hline & $\mathrm{TDF}+3 \mathrm{TC}+\mathrm{NVP}$ & $1(1.3)$ & - & - \\
\hline \multirow{6}{*}{$\begin{array}{l}\text { Number of participants by HAART } \\
\text { agent }\end{array}$} & $3 \mathrm{TC}$ & $75(100.0)$ & - & - \\
\hline & TDF & $50(66.7)$ & - & - \\
\hline & EFV & $49(65.3)$ & - & - \\
\hline & AZT & $25(33.3)$ & - & - \\
\hline & NVP & $24(32.0)$ & - & - \\
\hline & LPV+RTV & $2(2.7)$ & - & - \\
\hline
\end{tabular}

*CD4+ T cell count available only for 72 participants. *Number of participants by HAART agent (No).

Note: HAART - Highly Active Antiretroviral therapy. 
Metabolic syndrome was associated with cardiovascular disease risk among HIV-uninfected persons using the QRISK risk equation $(\mathrm{P}=0.029)$. HIV-uninfected participants at moderate cardiovascular risk using the QRISK calculator were more frequently diagnosed with metabolic syndrome based on IDF criteria than those at low cardiovascular risk with statistical significance $(4 / 8-50.0 \%$ vs. $8 / 52-15.4 \%$, $\mathrm{p}=0.029$ ) Table 2 .

Table 2. Prevalence of Cardiovascular risk based on Metabolic Syndrome status in HIV-uninfected participants.

\begin{tabular}{|c|c|c|c|c|c|c|c|}
\hline \multirow{2}{*}{ Parameter } & & \multicolumn{3}{|l|}{ QRISK } & \multirow{2}{*}{$\begin{array}{l}\text { Total } \\
(\mathrm{n}=60)\end{array}$} & \multirow{2}{*}{$X^{2}$} & \multirow{2}{*}{ P-value } \\
\hline & & Low $(n=52)$ & Moderate $(n=8)$ & High $(n=0)$ & & & \\
\hline HIV uninfected (IDF Criteria) & $\begin{array}{l}\text { Without MS } \\
\text { With MS }\end{array}$ & $\begin{array}{l}44(84.6) \\
8(15.4)\end{array}$ & $\begin{array}{l}4(50.0) \\
4(50.0)\end{array}$ & $\begin{array}{l}0(0.0) \\
0(0.0)\end{array}$ & $\begin{array}{l}48(80.0) \\
12(20.0)\end{array}$ & 10.778 & 0.029 \\
\hline
\end{tabular}

Note: MS - Metabolic syndrome, IDF - International Diabetes Federation, $\mathrm{X}^{2}$ - Chi square.

Metabolic syndrome was associated with cardiovascular disease risk among HIV-infected patients using the DAD risk equation only $(\mathrm{P}=<0.001)$. HIV-infected participants at moderate cardiovascular risk using the DAD risk calculator were more frequently diagnosed with metabolic syndrome based on IDF criteria than those at low risk with very high statistical significance $(5 / 19-26.3 \%$ vs. $12 / 55-21.8 \%$, $\mathrm{P}=<0.001$ ) Table 3 .

Table 3. Prevalence of Cardiovascular risk based on Metabolic Syndrome status in HIV-infected participants.

\begin{tabular}{|c|c|c|c|c|c|c|c|}
\hline \multirow{2}{*}{ Parameter } & & \multicolumn{3}{|l|}{ QRISK } & \multirow{2}{*}{$\begin{array}{l}\text { Total } \\
(n=75)\end{array}$} & \multirow{2}{*}{$\mathbf{X}^{2}$} & \multirow{2}{*}{ P-value } \\
\hline & & $\operatorname{Low}(n=70)$ & Moderate $(n=4)$ & High $(n=1)$ & & & \\
\hline \multirow{2}{*}{ HIV infected (IDF Criteria) } & Without MS & $53(75.7)$ & $4(100)$ & $1(100)$ & $58(77.3)$ & \multirow{2}{*}{4.703} & \multirow{2}{*}{0.319} \\
\hline & With MS & $17(24.3)$ & $0(0.0)$ & $0(0.0)$ & $17(22.7)$ & & \\
\hline \multirow{2}{*}{ Parameter } & & \multicolumn{3}{|l|}{ DAD RISK } & \multirow{2}{*}{$\begin{array}{l}\text { Total } \\
(n=75)\end{array}$} & \multirow{2}{*}{$\mathbf{X}^{2}$} & \multirow{2}{*}{ P-value } \\
\hline & & Low $(n=55)$ & Moderate $(n=19)$ & High $(n=1)$ & & & \\
\hline \multirow{2}{*}{ HIV infected (IDF Criteria) } & Without MS & $43(78.2)$ & $14(73.7)$ & $1(100)$ & $58(76.0)$ & \multirow{2}{*}{135.828} & \multirow{2}{*}{$<0.001$} \\
\hline & With MS & $12(21.8)$ & $5(26.3)$ & $0(0.0)$ & $17(22.7)$ & & \\
\hline
\end{tabular}

Note: MS - Metabolic syndrome, IDF - International Diabetes Federation, $\mathrm{X}^{2}$ - Chi square.

Binary logistic regression analysis showed that only gender was an independent predictor of metabolic syndrome (OR: 5.376, 95\% CI: 1.907-15.153; $\mathrm{P}=0.001)$. Furthermore, more participants aged $<60$ years $(100 \%$ vs. $91.5 \%$, $\mathrm{P}=0.375)$, with formal education ( $100 \%$ vs. $92.5 \%, \mathrm{P}=0.999)$, with insufficient fruits or vegetables intake $(79.3 \%$ vs. $66 \%$,
$\mathrm{P}=0.177$ ), with no vigorous physical activity (34.5\% vs. $19.8 \%, \mathrm{P}=0.100)$ or with family history of CVD $(27.6 \%$ vs. $17.0 \%, \mathrm{P}=0.204$ ) were frequently diagnosed with metabolic syndrome compared to those who did not develop metabolic syndrome but no association was observed between these predictors and metabolic syndrome (Table 4).

Table 4. Bivariate Analysis of Predictors of Metabolic Syndrome in the Study Population.

\begin{tabular}{|c|c|c|c|c|c|c|}
\hline \multirow[t]{2}{*}{ Parameter } & & \multicolumn{2}{|c|}{$\begin{array}{l}\text { Study participants (MS based on IDF } \\
\text { Criteria) }\end{array}$} & \multirow{2}{*}{$\begin{array}{l}\text { Total } \\
(n=135)\end{array}$} & \multirow[t]{2}{*}{ Crude OR (95\% CI) } & \multirow[t]{2}{*}{ P-value } \\
\hline & & Without MS $(n=106)$ & With MS (n=29) & & & \\
\hline \multirow{2}{*}{ Gender } & Male & $56(52.8)$ & $5(17.2)$ & $61(45.2)$ & $1.00(-)$ & - \\
\hline & Female & $50(47.2)$ & $24(82.8)$ & $74(54.8)$ & $5.376(1.907-15.153)$ & 0.001 \\
\hline \multirow{2}{*}{ Age } & $\geq 60$ years & $9(8.5)$ & $0(0.0)$ & $9(6.7)$ & $1.00(-)$ & - \\
\hline & $<60$ years & $97(91.5)$ & $29(100)$ & $126(93.3)$ & $0.385(0.47-3.170)$ & 0.375 \\
\hline Education & Formal & $98(92.5)$ & $29(100)$ & $127(94.1)$ & $1.00(-)$ & - \\
\hline \multirow{2}{*}{ Smoking } & No & $85(80.2)$ & $25(86.2)$ & $110(81.5)$ & $1.00(-)$ & - \\
\hline & Yes & $21(19.8)$ & $4(3.8)$ & $25(18.5)$ & $0.648(0.203-2.063)$ & 0.462 \\
\hline \multirow{2}{*}{ Vegetables/fruits intake } & Sufficient & $36(34.0)$ & $6(20.7)$ & $42(31.1)$ & $1.00(-)$ & - \\
\hline & Insufficient & $70(66.0)$ & $23(79.3)$ & $93(68.9)$ & $1.971(0.737-5.275)$ & 0.177 \\
\hline \multirow{2}{*}{ Vigorous physical activity } & Yes & $85(80.2)$ & $19(65.5)$ & $104(77.0)$ & $1.00(-)$ & - \\
\hline & No & $21(19.8)$ & $10(34.5)$ & $31(23.0)$ & $0.469(0.190-1.157)$ & 0.100 \\
\hline Family history of CVD & No & $88(83.0)$ & $21(72.4)$ & $109(80.7)$ & $1.00(-)$ & - \\
\hline
\end{tabular}

Note: MS - Metabolic syndrome, $\mathrm{X}^{2}$ - Chi square, OR - Odds Ratio, CVD - Cardiovascular disease.

Following multivariate analysis of predictors of metabolic syndrome whose $\mathrm{P}$ values were $<0.25$ (gender, vegetable or fruits intake, vigorous physical activity and family history of CVD) only gender was associated with metabolic syndrome and females were 7 times more likely to develop metabolic syndrome than males (OR: 6.958, CI: 2.317-20.896; $\mathrm{P}=0.001)$. On the contrary, vegetable or fruits intake, vigorous physical activity and family history of CVD were not associated with metabolic syndrome (Table 5). 
Table 5. Multivariate Analysis of Predictors of Metabolic Syndrome in the Study Population.

\begin{tabular}{|c|c|c|c|c|c|c|}
\hline \multirow{2}{*}{ Parameter } & & \multicolumn{2}{|c|}{ Study participants (MS based on IDF Criteria) } & \multirow{2}{*}{$\begin{array}{l}\text { Total } \\
(\mathrm{n}=135)\end{array}$} & \multirow{2}{*}{$\begin{array}{l}\text { Adjusted OR (95\% } \\
\text { CI) }\end{array}$} & \multirow{2}{*}{ P-value } \\
\hline & & Without MS (n=106) & With MS (n=29) & & & \\
\hline \multirow{2}{*}{ Gender } & Male & $56(52.8)$ & $5(17.2)$ & $61(45.2)$ & $1.00(-)$ & - \\
\hline & Female & $50(47.2)$ & $24(82.8)$ & $74(54.8)$ & $6.958(2.317-20.896)$ & 0.001 \\
\hline \multirow{2}{*}{ Vegetables/fruits intake } & Sufficient & $36(34.0)$ & $6(20.7)$ & $42(31.1)$ & $1.00(-)$ & \\
\hline & Insufficient & $70(66.0)$ & $23(79.3)$ & $93(68.9)$ & $2.819(0.973-8.172)$ & 0.056 \\
\hline \multirow{2}{*}{ Vigorous physical activity } & Yes & $85(80.2)$ & $19(65.5)$ & $31(23.0)$ & $1.00(-)$ & - \\
\hline & No & $21(19.8)$ & $10(34.5)$ & $104(77.0)$ & $2.597(0.946-7.129)$ & 0.064 \\
\hline \multirow{2}{*}{ Family history of CVD } & No & $88(83.0)$ & $21(72.4)$ & $109(80.7)$ & $1.00(-)$ & - \\
\hline & Yes & $18(17.0)$ & $8(27.6)$ & $26(19.3)$ & $1.462(0.510-4.193)$ & 0.480 \\
\hline
\end{tabular}

Note: MS - Metabolic syndrome, $\mathrm{X}^{2}$ - Chi square, OR - Odds Ratio, CVD - Cardiovascular disease.

\section{Discussion}

In this study, a significantly higher proportion $(26.3 \%)$ of HIV sero-positive patients at moderate cardiovascular risk had metabolic syndrome compared to the proportion $(21.8 \%)$ of patients at low risk for cardiovascular disease. Among the predictors (gender, vegetable or fruits intake, vigorous physical activity and family history of CVD) of metabolic syndrome in this research, gender was the only predictor associated with metabolic syndrome in both the HIV infected and uninfected individuals among whom females were 7 times more likely to develop metabolic syndrome than males.

This study revealed a higher proportion $(26.3 \%)$ of HIV sero-positive patients at moderate cardiovascular risk (DAD risk: $1-5 \%$ ) had metabolic syndrome compared to the proportion $(21.8 \%)$ of patients at low risk (DAD risk: $<1 \%$ ) for cardiovascular disease $(\mathrm{P}=<0.001)$. Similarly, Elizabete et al reported that metabolic syndrome is associated with a higher cardiovascular disease risk in HIV patients [16]. This similarity could be owing to the fact that both studies studied HAART experienced participants. A study conducted in Poland reported similar findings where a higher percentage (73\%) of HIV-infected patients with metabolic syndrome had intermediate $\mathrm{CV}$ risk compared to the percentage $(10 \%)$ of patients at low cardiovascular risk $(\mathrm{P}=0.006)$ [30]. Moreover, Latin American and American investigators estimated that HIV-infected individuals with metabolic syndrome were at a higher 10-year risk of developing cardiovascular disease using the Framingham 10-year risk calculator compared to those without [17, 18]. Conversely, Mariana and colleagues reported that more HIV patients at low risk had metabolic syndrome compared to those at moderate and high risk $(80 \%$ vs. $20 \%, p=0.22$ ) [19]. This difference is likely because Mariana and colleagues studied only HAART naïve HIV patients who were significantly younger whereas HAART drastically increases metabolic syndrome prevalence in HIV sero-positive patients and hence cardiovascular risk.

We highlighted in this study that gender was the only predictor of metabolic syndrome in both the HIV infected and uninfected individuals among whom females were 7 times more likely to develop metabolic syndrome than males (OR: 6.958, CI: 2.317-20.896; $\mathrm{P}=0.001$ ). Among the study participants with metabolic syndrome, more than threequarters $(82.8 \%)$ of them were females. Cultural factors like different diets in males compared to females may be a possible contributor. It could as well be explained by more women meeting the waist criteria compared to men or biological, hormonal and environmental factors that are thought to be contributing to the occurrence of metabolic syndrome in women. Our result is not in conformity with those of studies conducted in (Adjusted OR: 1.28, 95\% CI: 0.68-2.59; $\mathrm{P}=0.44$ ) Congo [8], (Crude OR: 1.38, 95\% CI: 0.77-2.46; $\mathrm{P}=0.278$ ) Kenya, (Univariate analysis: $\mathrm{P}=0.80$ ) Barcelona, and (Crude OR: 0.837, 95\% CI: 0.411-1.703; $\mathrm{P}=0.623)$ Ethiopia [20-22]. The contradictory findings reported by Patrick et al in Congo, Dula et al in Ethiopia and Carlos and colleagues in Barcelona might have stemmed from the fact that investigators from these three studies used the NCEP ATP III criteria to diagnose metabolic syndrome among HAART experienced HIV patients. Furthermore, the use of the harmonized Joint Scientific Statement criteria by Catherine et al in Kenya might account for the discrepancy in finding indicated in her study. However, our result is consistent with results revealed by studies conducted in the United States [1], Tanzania, Burkina Faso, Kenya, Nigeria, Ethiopia, and South Africa [23-28].

The sample size of HIV patients on HAART in this study was small due to a short study duration and small number of these patients who visited the HIV/AIDS treatment center daily. Despite these limitations, this study is the first in Cameroon (to the best of our knowledge) which shows that HAART experienced HIV patients diagnosed with metabolic syndrome have an increased cardiovascular risk and HIV infected and uninfected females are 7 times more likely to develop metabolic syndrome than their male counterparts.

\section{Conclusion}

A significantly higher proportion of HAART-treated HIV patients at moderate CVD risk are diagnosed with metabolic syndrome compared to those at low CVD risk. Gender is associated with metabolic syndrome in both HAARTexperienced HIV patients and HIV-uninfected individuals. HIV sero-positive females have higher chances of developing metabolic syndrome than their male counterparts. Early screening of HIV patients on HAART particularly females for metabolic syndrome after initiating them on HAART is recommended. 


\section{Conflict of Interest Statement}

The authors declare that they have no competing interests.

\section{Acknowledgements}

The authors appreciate the contributions made by the Chief Medical officer and laboratory staff at the Tiko Central Clinic and Cottage hospital. We are also grateful for the collaboration of the HAART treated HIV infected and HIV sero-negative participants in Tiko Central Clinic and Cottage hospital.

\section{References}

[1] Sabeena S, Justin RB, Sylvia O, Mina Q, Pascale W, Osaro M, et al. Metabolic Syndrome among people living with HIV receiving medical care in Southern United States: Prevalence and Risk factors. AIDS and Behavior 2019; 1-10.

[2] Jules CNA, Vigny N, Vincent SV, John FT, Peter A, Eric AA. Evaluation of cardiovascular risk factors in HIV/AIDS patients attending the Tiko Central Clinic and Cottage hospital, Tiko, Cameroon. On J Cardiovas Res 2019; 2 (3): 1-7.

[3] Sara P, Teresa R, Ana CM, Emilia V. Cardiovascular risk in HIV-infected individuals: A comparison of three risk prediction algorithms. Rev Port Cardiol 2019; 38 (7): 463470 .

[4] Angelica CP, Miguel ASA, Sara GJ, Eduardo PM, German BF Miguel CM, et al. Changes in cardiovascular risk and clinical outcomes in a HIV/AIDS cohort study over a 1-year period at a specialized clinic in Mexico. Therapeutics and Clinical Risk Management 2018; 14: 1757-1764.

[5] Handan W, Alexandra C, Dianne LC, Katherine S, Andrew C, Matthew GL, et al. Metabolic syndrome, cardiovascular disease and type 2 diabetes mellitus after initiation of antiretroviral therapy in HIV infection. AIDS 2007; 21: 24452453.

[6] Magdalena ES, Donald RH, Kathryn A, Kathleen M, Tianren T, Qiuhu Shi, et al. Prevalence and predictors of Metabolic Syndrome among HIV-Infected and HIV-Uninfected women in the women's Interagency HIV Study. $J$ Acquir Immune Defic Syndr 2008; 48 (3): 272-280.

[7] Mohammadtaghi S, Seyed JM, Masoud M, Seyedeh MN, Mohammad HS, Ali P, et al. The Incidence of Metabolic Syndrome and the Most Powerful Components as Predictors of Metabolic Syndrome in Central Iran: A 10-Year Follow-Up in a Cohort Study. Iran Red Crescent Med J 2017 (7); 19: e14934.

[8] Patrick DMCK, Friedrich T, Andre NHB, Tonya ME, Aime $\mathrm{BM}$, Pierre PML, et al. Prevalence and risk factors of metabolic syndrome in HIV-infected adults at three urban clinics in a post-conflict setting, eastern Democratic Republic of the Congo. Tropical Medicine and International Health 2018; 23 (7): 795-805.

[9] Olamide OT, Solange ZM, Benn S. Prevalence of metabolic syndrome among HIV-positive and HIV-negative populations in sub-Saharan Africa-a systematic review and meta-analysis. BMC 2019; 8 (4): 1-17.
[10] Herbert AM, Henry DM, Anthony TK, Omarine N, Theresia NK. Prevalence of metabolic syndrome in human immunodeficiency virus - infected patients from the SouthWest region of Cameroon, using the adult treatment panel III criteria. Diabetol Metab Syndr 2014; 6 (92): 1-7.

[11] UNAIDS. Cameroon: HIV/AIDS estimates. 2020. Available at: http://www.unaids.org/en/regionscountries/countries/Cameroo n.

[12] ONUSIDA. RAPPORT NATIONAL DE SUIVI DE LA DECLARATION POLITIQUE SUR LE VIH/SIDA CAMEROUN - Global AIDS Response Progress (GARP). Cameroon: ONUSIDA, 2014.

[13] IDF. The IDF world consensus definition of the metabolic syndrome. 2006. Available at: https:/www.idf.org/elibrary/consensus-statements/60-idfconsensus-worldwidedefinitionof-the-metabolic-syndrome.

[14] ClinRisk. Welcome to the QRISK ${ }^{\circledR 2-2016}$ risk calculator. 2016. Available at: https://qrisk.org.

[15] HIV Pharmacovegilance. Risk Evaluation Tools. 2007. Available at: https://www.hivpv.org.

[16] Elizabete SM, Marcela A, Christefany RBC, William S, Elucir $\mathrm{G}$, Renata KR. Evaluation of cardiovascular risk factors in people living with HIV in São Paulo, Brazil. JIDC 2020; 14 (1): 89-96.

[17] Clive RP, Bradley EA, Caryl G, Traci C, Irina M, Harvey D, et al. Metabolic Abnormalities and Coronary Heart Disease Risk in Human Immunodeficiency Virus-Infected Adults. METABOLIC SYNDROME AND RELATED DISORDERS 2010; 8 (3): 279-286.

[18] Alvarez C, Salazar R, Galindez J, Rangel F, Castaneda ML, Lopardo G, et al. Metabolic syndrome in HIV-infected patients receiving antiretroviral therapy in Latin America. Braz J Infect Dis 2010; 14 (3): 256-263.

[19] Mariana AR, Geyza NAA, Nathalia SG, Camila AC, Raissa DSS, Unai T. Metabolic disorders and cardiovascular risk in people living with HIV/AIDS without the use of antiretroviral therapy. Rev Soc Bras Med Trop 2017; 50 (5): 598-606.

[20] Catherine NK, Joyce NW, Elvis OO, Mark OO, Jane GM, Zeinab GR, et al. Prevalence and factors associated with metabolic syndrome in an urban population of adults living with HIV in Nairobi, Kenya. PAMJ 2018; 90 (90): $1-9$.

[21] Carlos G, Hernando K, Milagro M, Jordi OL, Ana G, Juan LG, et al. Metabolic Syndrome Among HIV-Infected Patients: Prevalence, characteristics, and related factors. Diabetes Care 2005; 28 (1): 132-137.

[22] Dula DB, Lemessa D, Teshale AM, Dawit AA, Mikyas GT, Tesfahun CE. Prevalence and predictors of metabolic syndrome among people living with human immunodeficiency virus (PLWHIV). Diabetol Metab Syndr 2018 (10); 10: 1-9.

[23] Gibson BK, Godfather DK, Clement NM, Andrew MK, Ray MM, Amani FS, et al. Prevalence and Risk Factors of Metabolic Syndrome among Individuals Living with HIV and Receiving Antiretroviral Treatment in Tanzania. BJMMR 2015; 5 (10): 1317-1327. 
[24] Oumar G, Herve T, Arnaud ED, Yempabou S, Ismael D, Bertille Y, et al. Features of Metabolic Syndrome and Its Associated Factors during Highly Active Antiretroviral Therapy in Ouagadougou (Burkina Faso). JIAPAC 2016; 15 (2): 159-163.

[25] Alfred O, Tecla MT, Nicholas K, Edmond KN, Jemima HK, Stephanie P, et al. Metabolic Syndrome Among Antiretroviral Therapy-Naïve Versus Experienced HIV-Infected Patients Without Preexisting Cardiometabolic Disorders in Western Kenya. AIDS PATIENT CARE and STDs 2018; 32 (6): 215222.

[26] Basile GS, Nicodeme WC, Victorien TD, Esther D, Arnaud NK, Veronique BTT, et al. Prevalence of metabolic syndrome and associated risk factors in the population of Southern Benin Int J Biosci 2019; 15 (5): 205-217.

[27] Agete TH, Demo YT. Influences of gender in metabolic syndrome and its components among people living with HIV virus using antiretroviral treatment in Hawassa, southern Ethiopia. BMC Res Notes 2016; 9 (145): 1-7.

[28] Eyitayo OO, Daniel TG, Oladele VA, Aanuoluwa OA, Eunice S. Prevalence and Correlates of Metabolic Syndrome Among Adults Attending Healthcare Facilities in Eastern Cape, South Africa. TOPHJ 2017; 10: 148-159.

[29] Julia HC, Carol C, Yana V, John R, Margaret M, Peter B. Derivation and validation of QRISK, a new cardiovascular disease risk score for the United Kingdom: prospective open cohort study. BMJ 2007; 1-12.

[30] Magdalena RP, Anna G, Pawel R, Mariusz L, Robert F. Metabolic syndrome in HIV infected adults in Poland. Kardiol Pol 2018 (3); 76: 548-553.

[31] Mark Mascolini. When and How to screen for cardiovascular disease risk in people with HIV. 2013. Available at: https://www.thebodypro.com. 